\title{
Seed Dormancy and Germination Requirements of Two Endemic Palm Species of Sri Lanka
}

\author{
Gama-Arachchige N.S. ${ }^{1,2 *}$, Alahakoon A.A.C.B. ${ }^{1,2}$ \\ ${ }^{1}$ Department of Botany, Faculty of Science, University of Peradeniya, Sri Lanka \\ ${ }^{2}$ Postgraduate Institute of Science, University of Peradeniya, Sri Lanka \\ *gnsu@pdn.ac.lk
}

\begin{abstract}
Sri Lankan endemic lowland rain forest palm species Areca concinna and Oncosperma fasciculatum are considered to be threatened due to habitat loss. Seed dormancy and germination behavior of these species are poorly understood. Therefore, the present study was conducted to identify the dormancy, germination requirements and the effect of storage time on dormancy alleviation of these species. Ripe fruits of $A$. concinna and $O$. fasciculatum were collected from home-gardens and natural populations. Initial moisture contents of fruits were measured. The effects of different gibberellic acid $\left(\mathrm{GA}_{3}\right)$ concentrations $(0,250,500,1000$, 2000, 3000 and $4000 \mathrm{ppm}$ ) and the removal of fruit coats and/or operculum on seed germination of both species were tested in vitro. The effects of wet storage (moist coir dust in sealed bags) at $25^{\circ} \mathrm{C}$ and dry storage (open trays) at ambient room temperature (approx. $29^{\circ}$ C) on seed dormancy break and seed viability were tested after 0, 3, 9 and 12 months. Fruit moisture of $A$. concinna and $O$. fasciculatum were approximately $15 \%$ and $30 \%$, respectively. Intact fruits of $A$. concinna treated with $500 \mathrm{ppm} \mathrm{GA}_{3}$, showed a significantly higher germination percentage $(88 \%)$ than $0 \mathrm{ppm}(33 \%)(\mathrm{P}<0.05)$.Intact fruits of $O$. fasciculatum did not respond to $\mathrm{GA}_{3}$ treatments, with $<4 \%$ germination. The highest germination percentages were achieved by removing pericarp+mesocarp+endocarp and 1000 ppm GA 3 application in A. concinna (89\%), and removing pericarp+mesocarp and operculum in $O$. fasciculatum (36\%). Seed viability of fresh A. concinna was $87 \%$ and remained high even after 12 months of dry storage while that of $O$. fasciculatum has declined to $2 \%$ from $85 \%$ after 6 months of dry storage. Seed germination percentages of intact $A$. concinna and $O$. fasciculatum after 12 months of dry storage were $20 \%$ and $0 \%$ respectively. Seeds of A. concinna stored wet at $25^{\circ} \mathrm{C}$ germinated slowly during 12 month period reaching $22 \%$. Seeds of $O$. fasciculatum showed a similar pattern reaching $36 \%$. It can be concluded that both species exhibit physiological dormancy. $O$. fasciculatum was identified as recalcitrant while A. concinnaas orthodox. Seed germination of $A$. concinna can be promoted by removing all fruit coats and $\mathrm{GA}_{3}$ treatment whereas in $O$. fasciculatum by removing the operculumor storing seeds in moist coir dust for $>6$ months. These findings will be useful in producing seedlings for restoration of these species.
\end{abstract}

Keywords: Areca, Oncosperma, Orthodox, Physiological dormancy, Recalcitrant 